\title{
Externalities of Public Housing: The Effect of Public Housing Demolitions on Local Crime
}

\author{
by
}

\author{
Danielle H. Sandler \\ U.S. Census Bureau
}

\begin{abstract}
CES 16-16
March, 2016

The research program of the Center for Economic Studies (CES) produces a wide range of economic analyses to improve the statistical programs of the U.S. Census Bureau. Many of these analyses take the form of CES research papers. The papers have not undergone the review accorded Census Bureau publications and no endorsement should be inferred. Any opinions and conclusions expressed herein are those of the author(s) and do not necessarily represent the views of the U.S. Census Bureau. All results have been reviewed to ensure that no confidential information is disclosed. Republication in whole or part must be cleared with the authors.

To obtain information about the series, see www.census.gov/ces or contact Fariha Kamal, Editor, Discussion Papers, U.S. Census Bureau, Center for Economic Studies 2K132B, 4600 Silver Hill Road, Washington, DC 20233, CES.Papers.List@census.gov. To subscribe to the series, please click here.
\end{abstract}




\begin{abstract}
This paper evaluates the potential for negative externalities from public housing by examining crime rates before and after demolition of public housing projects in Chicago between 1995 and 2010. Using data on block-level crimes by type of crime merged to detailed geographic data on individual public housing demolitions, I find evidence that Chicago's public housing imposed significant externalities on the surrounding neighborhood. Using a difference in difference approach comparing neighborhoods around public housing projects to nearby neighborhoods I find that crime decreases by $8.8 \%$ after a demolition. This decrease is concentrated in violent crime. I use an event study to show that the decrease occurs at the approximate date of the eviction of the residents and persists for at least 5 years after the demolition. Neighborhoods with large demolitions and demolitions of public housing that had been poorly maintained display the largest crime decreases.
\end{abstract}

I would like to thank Hilary Hoynes, Doug Miller, Scott Carrell, Marianne Page, Victor Stango, Mark Kutzbach, seminar participants at University of California-Davis, Sonoma State, the Conference on Urban Mass Housing, the Bureau of Labor Statistics, and several anonymous referees for their helpful comments. I also acknowledge the Chicago Housing Authority and the Chicago Police Department for providing data for this project and nancial support from the Institute for Governmental Affairs Dissertation Improvement Grant. Any opinions and conclusions expressed herein are those of the author and do not necessarily represent the views of the U.S. Census Bureau. The research in this paper does not use any confidential Census Bureau information. 


\section{Introduction}

In the 1930s, cities in the United States began providing subsidized, government-run rental housing to give temporary shelter to those whom the market fluctuations of the era left homeless. Since then, US public housing has gone through a number of changes, most recently including defunding, deterioration, and social decay. Many consider the program a failure due to the high crime rates, gang problems, and public health issues observed in many of the large public housing projects built in the 1950s and 1960s (Hunt 2009). The gradual defunding of the US public housing program provides a natural experiment to explore the effect of this housing on the community. The quality of public housing has declined to such an extent that cities have begun to demolish it with help from the federal government. These demolitions result in a sudden removal of public housing projects from a geographic location.

As of the mid-90s, Chicago had the third largest public housing stock of the United States, exceeded only by New York and Puerto Rico, and the most troubled public housing of any city in the country due to the heavy influence of gangs and periods of mismanagement by the housing authority (Popkin, Gwiasda, Amendolia and Anderson 1996). Chicago began demolishing its troubled and troublesome public housing high-rises beginning in August 1995 and continued to demolish and rebuild for the next 15 years, working in earnest starting in 2000 with the beginning of the Chicago Housing Authority's "Plan for Transformation." The size and length of Chicago's demolition program makes it ideal for studying the effect of public housing on the surrounding neighborhood.

This paper focuses on neighborhood as the unit of analysis and shows the effect of the demolitions on neighborhood crime rates. Anecdotally, crime rates are very high in public housing neighborhoods. Public housing complexes concentrate problems that already exist in the urban landscape. If the structure and culture of the public housing complexes increases crime rates, we would expect crime to go down when the buildings are demolished. On the other hand, if public housing simply concentrates crime, a demolition may cause a redistribution of crime without a global decrease. From a crime control perspective, both changes in crime are important because they would necessitate changes in policing patterns; however a global decrease in crime is clearly the more welfare-enhancing outcome.

I assemble and use a novel block-level dataset containing crimes committed in Chicago between 1999 and 2011 to look at the effect of demolitions on local crime levels. I find that 
crime levels decrease after a demolition in the area immediately surrounding the demolition relative to areas farther away. I employ a modified difference in difference identification strategy that uses a continuous treatment scaled by the number of units demolished to allow for multiple treatments of different sizes per block. The estimates show that crime decreases by $2.4 \%$ within a quarter mile of a demolition. This result attenuates when I include blocks that are farther away from the demolition in the treatment area, but remains statistically distinguishable from zero. The decrease in the number of crimes committed is observable across all types of serious crimes, but violent crimes exhibit the largest percent decreases. An event study shows that the decrease in crimes occurs approximately at the time that the residents are evicted from their housing units prior to the demolition and persists for at least five years following the demolition. The majority of the public housing population displaced by the demolition moves within 2 miles of their previous home, but there is no observed increase in crime in this area, therefore the observed decrease appears to be a true decrease rather than a redistribution of criminals or victims.

This paper builds on the work by Aliprantis and Hartley (2015), who also find a decrease in crime following the demolition of public housing high rises in Chicago. The results here are consistent with their findings and build on these findings by beginning the exploration of the mechanisms behind the crime decrease by exploring the heterogeneity of the findings over characteristics of the neighborhood and characteristics of the demolished buildings themselves.

These results are a complement to the small body of existing research on public housing in the economics literature. Eriksen and Rosenthal (2010) also examine the neighborhoods around the time of a change in low income housing supply, but use the building of housing incentivized by the Low Income Tax Credit (LITC) as their source of variation. They find increases in house prices when the LITCs are used in low-income areas, but decreases in high-income areas.

Most other research focuses on the public housing residents, rather than on the neighborhood. Much of this research comes from the Moving to Opportunity (MTO) demonstrations conducted in the 1990s 1 The results of these experiments are mixed. Although former

\footnotetext{
${ }^{1}$ In these experiments, researchers randomly selected public housing residents from a pool of volunteers to receive Section 8 housing vouchers that allowed them to rent housing in the private market. The researchers then followed these randomly selected residents and compared them to the sample of individuals that volunteered for the demonstration but did not receive vouchers.
} 
public housing residents live in safer neighborhoods and have improved mental health, their economic self-sufficiency and physical health did not change relative to the control population (Kling, Liebman and Katz 2007). Violent crime arrests went down temporarily for the treated population (Ludwig, Duncan and Hirschfield 2001), but property crimes went up in the long run (Kling, Ludwig and Katz 2005). Treated youth showed small gains in academic achievement (Sanbonmatsu, Kling, Duncan and Brooks-Gunn 2006). More recent literature uses other randomized voucher distributions. Jacob, Ludwig and Miller (2013) find death rates of youth decrease and Jacob and Ludwig (2012) find labor supply decreases as a result of the receipt of housing vouchers in Chicago. Andersson, Haltiwanger, Kutzbach, Palloni, Pollakowski and Weinberg (2013) find within family benefits for children living in subsidized housing, especially voucher-supported housing.

While the MTO research provides a great deal of insight into the behavior of public housing residents during a move to a new neighborhood, the policy experiment of a housing demolition is quite different from a small volunteer voucher program. Many more people are required to move in a demolition and the individuals moved are not volunteers. Few other papers in the literature look at the variation in public housing caused by public housing demolitions. Jacob (2004) uses the same policy experiment used in this paper to look at how school achievement changes for children in Chicago who are moved from a public housing complex due to a demolition. He finds only a small effect of this move on achievement.

The next section discusses some of the background on public housing in general, as well as Chicago's public housing specifically. In Section 3, I describe my data. The analysis is divided in three parts. Section 4 establishes the existence of a local crime decrease after

a public housing demolition, Section 5 explores the timing of this decrease, and Section 6 investigates some of the heterogeneity in the estimated results to understand the viability of several potential mechanisms for the observed decrease in crime. Section 7 concludes.

\section{Public Housing Background}

The United States' public housing program was originally intended to provide short-term housing for individuals and families when they could not afford housing in the private market due to unemployment, poor health, or other fluctuations in income. The character of public housing changed within a few decades as housing authorities built large projects to provide 
a long-term housing alternative to the urban ghetto for both the working poor and families on public assistance (Venkatesh 2000).

The nature of the nation's public housing changed yet again as funding for public housing declined and maintenance levels fell during the 1980s and 1990s. Many families moved out of public housing. Those were left behind were the most troubled families with nowhere else to go. These individuals were rougher on the units and less likely to demand maintenance when needed, so the buildings fell further into disrepair. National Commission On Severely Distressed Public Housing (1992) found that 86,000 units of the nations' public housing stock were in need of major renovation or demolition as of the early 1990\$2

Partially due to the Commission's findings, Congress approved the HOPE VI program, which was intended to fund demolition and rehabilitation of the severely distressed public housing stock. During the first 10 years of the HOPE VI program the Department of Housing and Urban Development (HUD) provided $\$ 395$ million in HOPE VI demolition grants to demolish 57,000 severely distressed housing units. Chicago received a large number of these grants.

Chicago began demolishing its distressed housing in 1995 with its first HOPE VI grants, but started demolishing in earnest in 2000 after the introduction of their "Plan for Transformation". There were several reasons for this increased attention in 2000. Several high-profile murders occurred in the housing projects, which drew Chicago's troubled housing into the national spotlight (Kirby 1992, Gleick and Grace 1997, Kuczka and McRoberts 1994). A new federal law (Section 202 of the Omnibus Consolidated Rescissions and Appropriations Act) required cities to evaluate their public housing stock and demolish any projects that the housing authority could not revitalize for less than it would cost to give all of the residents housing vouchers for a period of 20 years. Much of Chicago's public housing failed this test. Congress also loosened restrictions on replacement housing. Prior to this change, public housing authorities were required to replace every housing unit demolished with new housing, but the change allowed them to only replace the units that were occupied at the

\footnotetext{
${ }^{2}$ The Commission used a wide span of indicators to evaluate whether or not a public housing complex was severely distressed. These include comparisons between the housing project and the city, including the project unemployment rate, the project high school dropout rate, and the project crime rate. They also looked at measures of management deficiencies including vacancy and turnover rates, the estimated reconstruction cost, and annual average work order backlog. These were in addition to the signs that the building was falling apart, such as lead paint chipping in more than $20 \%$ of the units, lack of heat or hot water, and leaking roof or plumbing (National Commission On Severely Distressed Public Housing 1992).
} 
time of the building closure. This made a demolition program more feasible in Chicago, whose worst housing projects had a 45\% occupancy rate (Buron and Popkin 2010).

The goal of the Plan for Transformation was to eliminate the medium and high-rise public housing and replace it with low-rise, mixed income housing. Critics of the Plan argued that the demolitions did not result in better housing for residents. The vouchers the housing authority provided to many of the residents did not pay enough for residents to afford housing in good neighborhoods. Venkatesh, Celimi and Turner (2002) found that $24 \%$ of residents whose project was demolished ended up back in another project. Other residents from public housing demolitions ended up in private housing, typically as renters. Buron and Popkin (2010) found that 54\% of former public housing residents rented with a voucher, and $15 \%$ rented unassisted. The former residents were spread throughout the city, but were primarily located in low-income areas. Venkatesh, Çelimli, Miller, Murphy and Turner (2004) found that $97 \%$ of former residents were in low-income and/or minority neighborhoods after relocation. Many did not move far from their previous home, or came

back to the old neighborhood regularly. A quarter of the children remained in the same school.

\section{Data}

The data for this study come from a variety of sources. The Chicago Housing Authority (CHA) provided demolition dates and the number of units demolished from 1995 to 2010. Figure 1 shows the location of the 22 public housing projects that were demolished between 1995 and 2000. The projects are concentrated in the heart of the city, especially in the "South Side," near Lake Michigan and the "West Side."

Table 1 shows the distribution of demolitions over time. Although there were only 22 projects demolished, the CHA demolished most of them in several stages. Each of these 22 projects is a complex with multiple buildings and, typically, one building is demolished at a time. Table 2 gives the number of demolitions for each project. For consistency, I refer to these named complexes as "projects," the individual buildings in a project simply as "buildings" and a single apartment in a building as a "unit" throughout the paper. Although there are some smaller demolitions, the typical demolition is over 100 units. Since most of the units are three or four bedrooms, intended for two people per bedroom, each of these 
demolitions move hundreds of people, even if the building was only half full at the time of demolition. My analysis only includes residential buildings, although many non-dwelling buildings were demolished as well.

Figure 2 gives an approximate timeline of a demolition. The structural demolition date is when the building is destroyed, the demolition completion date is when work on the demolition is complete and the land is ready for its new use. The demolition completion date occurs, on average, six months after the structural demolition date. The time between building closure and structural demolition is typically around 2 months ${ }^{3}$ It is CHA policy to distribute eviction notices at least 90 days before a building closure. There are two unknown dates that may be relevant to this paper, the date of announcement for the demolition of a particular building and the reconstruction date. Despite discussions with officials at the CHA, these dates are unavailable and possibly unknowable. The CHA provided data on two dates that could be used as my treatment date, the structural demolition date and the demolition completion date. I use the structural demolition date as the date my treatment begins in my estimation, but my estimates are not sensitive to using a two month lead of this date instead, which would approximate the building closure date.

I geocoded the demolished public housing addresses provided by the CHA using a combination of Google maps and maps of the city available from the city of Chicago. If there is no building of the exact address available on either map, which occurs if the building has been demolished and not yet replaced, I use a building on the same block instead. Each demolition can include several buildings. If buildings from the same demolition (defined as the same demolition date and project) are on multiple blocks, I use the centermost location.

Crime data include all reported index ${ }^{4}$ crimes occurring within the City of Chicago from January 1999 to February 2011, which I obtained from the Chicago Police Department through a Freedom of Information Act request. The data are incident-level, with date and block of incident, and I aggregate to totals by month and block for the analysis. I show the average numbers of crimes per block per month for blocks close to the demolitions in Table 3. There are 0.881 crimes per block per month on blocks within 3 miles of a demolition. The number of crimes per block is slightly higher on blocks closer to a demolition. Crime of all

\footnotetext{
${ }^{3}$ Estimated time between building closure and structural demolitions derived from personal communications with officials at the CHA

${ }^{4} \mathrm{An}$ index crime is a crime in one of the 8 crime categories used to create crime rates by the FBI. These crime categories are murder, rape, assault, robbery, burglary, theft, car theft, and arson.
} 
types decreased in Chicago from 1999 to 2010. Figure 3 shows this decline by crime type, where violent crime includes murder, assault, and rape, and Table 4 shows the downward trend at blocks within a quarter mile of a public housing demolition. Figure 3 also shows the cumulative number of units demolished. The opposing trends in demolitions and crime imply a simple analysis using the time-series variation would be biased upward; therefore a more sophisticated source of identification is necessary. I use a difference in difference approach to avoid this potential source of bias.

The location of the crime is the city block of occurrence for most crimes. The information on location of any of these crimes may be subject to some measurement error when the police must rely upon the victim's recollection to identify the location. The crime data from the Chicago Police were professionally geocoded by Locative Technology $5^{5}$ using their proprietary GIS maps and supplemented by Google maps for harder to match locations. From this geolocated data, I calculated the distance between public housing demolition sites and city block using Euclidian distance. I use this measure of distance to assign the treatment of a demolition to a given block.

\section{Difference in Difference}

\subsection{Estimation Strategy}

The public housing demolitions in Chicago provide variation in time, space and scope, which I exploit in my estimation strategy. To motivate the estimation strategy, consider a simplified setting where each neighborhood has at most one demolition in the sample period. In this case, I could use a simple difference in difference specification, as in the following equation.

$$
Y_{b t}=\alpha+\beta \text { Treated }_{b} * \text { Post }_{t}+\gamma_{t}+\psi_{b}+\varepsilon_{b t}
$$

where $b$ is the block and $t$ is time in months.6 Since the treatment/control status is constant within block, I can control for it with block fixed effects $\left(\psi_{b}\right)$ in the above equation. Similarly, a before/after variable could be specified for all blocks, or could be captured by

\footnotetext{
${ }^{5}$ Locative Technology: Website Geocoder.US

${ }^{6}$ I use block as my geography in my discussion, but it could also be neighborhood or census tract, when appropriate. The blocks here and in my analysis are actually street faces, rather than either city blocks or Census blocks. I use the term block for convenience.
} 
a month fixed effect $\left(\gamma_{t}\right)$. Treated Tr $*$ Post $_{t}$ is the traditional treatment interaction variable, a dummy variable that turns to one after the demolition for any blocks that are treated by the demolition.

However, the variation in my data is more complicated than what is captured in a simple difference in difference specification. First, many blocks do not have a single nearby demolition, but experience multiple demolitions over time. The difference in difference framework can handle multiple treatments if they occur in mutually exclusive areas, for instance if states implement a new law at different times, but Chicago's demolitions are often close enough together that they cause a given block or neighborhood to be treated multiple times.

The second complication is that the scale of the treatment varies between treatments. A demolition of 300 units is likely to have a larger effect than a demolition of 80 units. Instead of using a dummy variable to measure my treatment, I use a variable that increases by the number of units demolished every time there is a demolition. This cumulative treatment variable takes both the size of the demolition and the existence of multiple demolitions into account.

My estimating equation is the following

$$
Y_{b t}=\alpha+\beta_{1} U_{n i t} s_{b t}+\gamma_{t}+\psi_{b}+\theta_{c} t+\varepsilon_{b t}
$$

The Units $s_{b t}$ variable is a count of the number of units that have been demolished through date $t$ "near" block $b$. In my models, I vary the definition of "near" in defining the Units $s_{b t}$ variable. I explain this assignment of treatment status more in the next section.

\subsubsection{Assignment of Treatment}

With block-level crime data, the assignment of treatment status is not straightforward, since blocks in addition to the block were the demolition occurred will be affected by the demolition. I assign treated status according to distance. In Figure 4, I show three example blocks with one demolition nearby for each block. The block centroid is the square in the center of the diagram and the public housing demolition is the star. The block is treated if the demolition occurs within the first circle, which I call the treatment radius. The treatment at time $t$ will be the cumulative number of units demolished within the treatment radius by time $t$. Any blocks that have no demolition within their treatment radius, but have a demolition 
within the larger circle, the sample radius, remain in the sample as controls. Blocks far away from the demolition may be different from those nearby due to the heterogeneity in population in different areas of Chicago. Therefore, any blocks that have no demolitions within their sample radius are excluded from the sample. I report results for a variety of sizes of both radii, but my preferred specification uses a treatment radius of $1 / 4$ mile and a sample radius of 3 miles. To picture these distances in the map in Figure 1, the sample radius is around half the width of the city at the narrowest point, so my sample includes all of the "South Side" that contains the bulk of the demolitions as well as the area to the west, but excludes the extreme north and south portions of the city.

\subsubsection{Threats to Identification}

All specifications include block fixed effects $\left(\psi_{b}\right)$, which control for anything that is constant within blocks. I also include month fixed effects $\left(\gamma_{t}\right)$. These control for anything that is changing over time or is unique to a specific month for all blocks. Thus, the identifying variation is the timing and scale of demolitions across blocks. This is a valid causal estimate of public housing demolitions as long as the timing is not correlated with other factors affecting crime. I would like to control for block level linear trends, but that is not feasible due to the limited variation at the block level. I do the next best approach and use census tract linear trends, $\theta_{c} t$ in the above equation. These census-tract specific trends control for differences in trends for blocks in different census tracts. A census tract contains, on average, around 20 city blocks.

One reason we might see a within census tract difference in trends is if demolition sites were chosen endogenously, for instance if the choice to demolish a particular building was made in response to a change in the crime rate. There are several reasons this endogenous selection is unlikely. To begin with, the response must be to trends in crime, not just a generally higher (or lower) crime rate. A high crime rate is a constant at the block level, thus will be captured by block fixed effects. There is some evidence that some projects were chosen as early demolitions because of their infamously high levels of crime (Venkatesh 2000), but not to a change in crime rates.

This endogenous selection is likely to be most prevalent in the early period of demolitions, between 1995 and 2000, prior to the Plan for Transformation. Due to data availability on my outcomes of interest, the earliest demolitions, those before 1999, do not contribute to 
the identification. In addition, my identification comes from individual buildings within a project, rather than from the demolition dates and locations of entire projects. While the selection of projects to demolish may be a strategic decision, the decision of the order in which to demolish particular buildings within a project is more likely a logistical or engineering decision.

In addition, I am most concerned about endogenous selection based on a decreasing crime rate, rather than an increasing rate. Since a demolition is expected to decrease crime, selection of demolition sites based on an increasing crime rate, which is more politically likely, would bias my estimates towards zero.

\subsection{Results}

Table 5 shows the estimates from the specification detailed in the previous section for treatment radii of $1 / 4$ mile, $1 / 2$ mile, $3 / 4$ miles, and 1 mile, all with a sample radius of 3 miles. The main treatment variable is the number of units demolished within the treatment radius of a given block through period $t$. The coefficient on this variable is negative and statistically significant at all treatment radii and for all crime types. Standard errors are clustered at the block level, but remain quantitatively similar if clustered at the census tract level.

For the smallest treatment radius, $1 / 4$ mile, total crime decreases by 0.047 crimes per block per month for every 100 units demolished. The coefficients decline as blocks further away from the demolition are included in the treatment area while the 3 mile sample radius

remains constant, but remain negative and statistically distinguishable from zero. Table 6 scales the coefficients to reflect the effect of an average sized demolition, for ease of interpretation. Total crime decreases by 0.0748 crimes per block per month for an average-sized demolition, a $8.79 \%$ decrease relative to the average total crime per block. The effect is concentrated in violent crimes. Murders decrease by $31.4 \%$, assaults decrease by $32.4 \%$ and robberies decrease by $16.9 \%$. Burglaries and thefts decline by a more modest $4.17 \%$ and $3.88 \%$, respectively.

From Table 5 my results appear highly localized. My estimated treatment effect falls from -0.047 per block-month when I include blocks within 1/4 mile in the treatment radius to -.003 per block-month when I include all blocks within a mile of a demolition. I further explore the locality of my results in Table 8. In this table, the regression contains the 
treatment variables for two radii at a time. When estimated in the same regression, the coefficient on the smallest treatment radius gives the effect of the demolition within a small circle around the demolition. The coefficient on the second gives the effect of the demolition on the ring around the smaller circle, since the change within the circle is captured by the first variable. From the table, we see that the $1 / 4$ mile radius contains most of the estimated effect of the demolition. The smaller radius captures the bulk of decline in crime in every regression in this table, including the one that includes both a quarter and a half mile radii. More importantly, the results show no significant increases in crime within 2 miles around a demolition. The demolition is not causing crime to simply redistribute to areas further away. Most residents do not move far from the demolitions (Venkatesh et al. 2004), but some residents are moved further away by the Chicago Housing Authority, when they are transferred to another public housing complex. The lack of crime increase in the 2 mile radius gives some evidence that the observed decline in crime is a true decline, not a spatial redistribution.

\subsection{Robustness Checks}

\subsubsection{Sample Radius}

My preferred choice for the sample radius, used in all of the above specifications, is a radius of 3 miles. This choice includes a large portion of the city as a comparison group but avoids areas that are geographically and socioeconomically very different from the locations I am studying. However, due to the heterogeneity of Chicago's neighborhoods, even 3 miles may include areas that do not serve as good controls for my blocks of interest because they are on very different crime time trends. My results, however, are not sensitive to the choice of this radius. Table 9 shows the most conservative sample radius choice, in which I eliminate the control group entirely. Thus, the treatment radius and the sample radius are equal in this specification. These estimates use the variation in timing of demolitions as the source of identification, with later treated blocks serving as control for earlier treated blocks. The results I find with this specification are qualitatively similar to that of the main specification. 


\subsubsection{Alternate Specifications}

The continuous treatment variable scaled by units is only one of several specification choices I could have made for my main results. Table 11 contains several alternate specifications for both the treatment and dependent variable. The second column contains a traditional difference-in-difference estimate, where the treatment changes from zero to one with the first demolition and remains equal to one from then on. Without taking advantage of the variation from multiple demolitions with differing sizes, the estimated effect on crime is much smaller, and the coefficient is, in fact, positive for large radii.

The third column uses the modified difference in difference estimation technique but includes no control for census tract specific trends. The coefficient on the treatment variable is larger in magnitude than that of my main estimates, thus without these controls for the trends in differing locations, I would overestimate the effects of a demolition.

The fourth column uses an inverse hyperbolic sine (IHS) transformation of the dependent variable. This transformation allows for the interpretation of regression coefficients like in a log transformation, but unlike logs, the inverse hyperbolic sine is defined at zero. The inverse hyperbolic sine is defined as $y_{b t}^{*}=\log \left[y_{b t}+\left(y_{b t}^{2}+1\right)^{(1 / 2)]}\right.$ where $y_{b t}$ is the number of crimes in block $b$ and month $t$ (Burbidge, Magee and Robb 1988). The IHS transformation specification gives a smaller, $2.4 \%$, decrease in crime from a demolition, but it remains negative and significant.

Counts of crime at the block-level include a large number of zeros and generally leftskewed distribution, thus a Poisson or negative binomial model may be a better fit than either a linear regression or the IHS transformation. Column 4 of Table 11 shows the estimated marginal effects from a Poisson regression of total crime on the treatment variables estimated using maximum likelihood. The marginal effects are calculated at the mean of total crime, for 100 units demolished. The Poisson shows a 7.1\% 7 decrease in total crime within a quarter mile of the demolition. Which is smaller than the $8.8 \%$ estimate from the main specification, but is of a consistent magnitude.

\footnotetext{
${ }^{7}$ The marginal effects are calculated using the equation $m f x=\left(e^{\hat{\beta}}-1\right)$
} 


\subsubsection{Timing}

I use the structural demolition date as my treatment date for most of my specifications both because that is the date available in the data provided by the Chicago Housing Authority and because it is the date in which the most tangible change occurs at the demolition site. However, a demolition is a process, not a single event, so I explore the estimates using other potential treatment dates in Table 10. The estimates are largest if the estimated eviction date is used instead of the structural demolition date as the date of treatment. I explore the timing of the treatment further in section 5 with an event-study specification.

\section{$5 \quad$ Event Study}

\subsection{Estimation Strategy}

My main results show that crime decreases by $8.8 \%$ in the area within a quarter mile of a demolition but does not provide any insight into the timing of that decline. To directly examine the timing of the effect, I focus on the effect of a demolition on total crime in the quarter mile treatment radius. I do an event study analysis, using blocks that are not currently experiencing a demolition (but will or have already) as controls. I use the date of the structural demolition as the event date and the $1 / 4$ mile treatment area to estimate the following equation.

$$
Y_{b t}=\sum_{j}^{J_{b}} \sum_{d=-D}^{D} \pi_{d} 1\left(t-e_{j}^{b}=d\right)+\gamma_{t}+\psi_{b}+\theta_{c} t+\varepsilon_{b t}
$$

Where $1\left(t-e_{j}^{b}=d\right)$ is a series of dummy variables that indicate the length of time between the event and the date of the current observation, with $t$ indicating the date of the current observation and $e_{j}^{b}$ indicating the date of each event that effects block $b$. For ease of exposition, henceforth $\Gamma_{d}=1\left(t-e_{j}^{b}=d\right)$.

The standard specification for an event study with one event per cross sectional unit has set of mutually exclusive dummy variables, each equal to one when an event is a certain number of periods away. This basic specification extends directly to this setting, in which I have multiple events per cross sectional unit, only the dummies are not mutually exclusive, 
so that if a given individual in a given period is both three periods after an event and two periods before another event, both relevant dummies are equal to 1 . In this setting, if a demolition occurred 3 months ago and another will occur in 2 months then both $\Gamma_{3}=1$ and $\Gamma_{-2}=1$ and all other dummy variables will be equal to zero..$^{8}$

\subsection{Results}

I present the results of the event study analysis both graphically in Figures 5 and 6 and as a table in Table 12, Figure 5 shows the coefficients on the event time dummy variables for a 24 month window around the structural demolition date. Each point on the graph represents two months. I have adjusted the coefficients to be relative to the structural demolition date, which is set to zero. On this graph I have marked the approximate dates from the timeline of a typical demolition. Figure 6 shows that most of the crime decrease occurs between the time that eviction notices are mailed and the demolition completion date. This is consistent with the findings in Table 10, in which I find the largest estimated crime decreases if I use the approximate eviction date rather than the structural demolition date as my treatment date. Thus, my main estimates are an underestimate of the effect of these demolitions on crime.

The size of the effect seen in Figure 5 is consistent with the main estimates from the difference in difference approach. The estimates from Figure 5 are replicated in Table 12 . Unlike in the figure, the estimates in the table are not redefined to have the estimate at the structural demolition date equal to 0, thus the easiest way to interpret this regression is to compare coefficients, rather than comparing each coefficient to zero. The coefficient for the dummy variable at the approximate eviction date (5-6 months prior to the structural demolition date) is 0.050 , which is 0.060 crimes more than the estimated coefficient at $1-2$ months after the demolition date $(-0.010)$. This is consistent with Table 5 , in which I estimated a decrease of 0.047 crimes per block in $1 / 4$ mile radius of a demolition.

In addition to understanding the timing of a treatment, event studies allow for rigorous evaluation of pre-trends that may invalidate the identification of the estimates using a difference in difference approach. They also allow us to evaluate whether the event caused

\footnotetext{
${ }^{8}$ Other methods of handling the additional events produce spurious trends in the event-time dummies before and after the event, which can cast doubt on the identification of a valid event study, or indicate a real result where there is none. For more information see (Sandler and Sandler 2014).
} 
a temporary or permanent change in the outcome variable. Figure 6 shows a longer run graph of 5 years for evaluation of these potential pre and post trends. There are fewer observations supporting the estimates for the period before the demolition, especially for 4 and 5 years before the demolitions, which explains why these estimates vary more than the post-demolition estimates. Many of the demolitions occurred in 2001 and 2002, 3-4 years after the beginning of the crime data in 1999. Even with the additional noise, there does not appear to be a strong pre-trend, validating the identification of the main estimates. There is no post-trend in the 5 years after the demolition, thus the change in crime appears to be permanent, at least in the medium term.

\section{Heterogeneity \& Potential Mechanisms}

The previous results focused on the size and location of the crime decreases in the area around public housing, but provide little understanding of the mechanism behind the estimated decrease. This section explores the heterogeneity of the results over both neighborhood characteristics and the characteristics of the public housing itself. The literature points to several potential mechanisms behind the crime decrease observed with the demolition of public housing. The structure of the public housing may have contributed to the high crime near public housing, as the structures were mainly high rises, which limited the number of "eyes on the street" as discussed in Jacobs (1961) amongst other places and limited the existence of "defensible space" (Newman 1972). They were also places of very high

population density, a characteristic that has been associated with high crime in the literature (Glaeser and Sacerdote 1999). Much of the public housing was in disrepair, often in visible ways. A broad literature points the effect of broken windows and other signs of societal negligence as a correlate of high crime (Corman and Mocan 2005).

Tables 13 and 14 cast some light on these potential mechanisms by exploring the heterogeneity of the results over different neighborhood and public housing characteristics. The results in these tables come from the following specification:

$$
Y_{b t}=\sum_{q=1}^{Q} \beta_{q} * \text { Units }_{b t} * \text { Quantile }_{q}+\gamma_{t}+\psi_{b}+\theta_{c} t+\varepsilon_{b t}
$$


where the treatment variable is interacted with quantiles (or other defined categories) of Census tract or public housing characteristics.

Table 13 shows results for characteristics of the public housing itself. Although all of these demolitions were of public housing that was in disrepair, some projects were in worse shape than others. The Department of Housing and Urban Development inspects all public housing at regular intervals. I use HUD inspection scores of the quality of the project closest to the demolition date as a measure of the disrepair of the demolished housing prior to demolition. The estimated crime decreases after demolition are largest for the public housing in the worst shape prior to the demolition. Table 13 also shows the estimated effect for demolitions categorized as small, medium, or large. The estimated effect of demolishing public housing appears to be concentrated in demolitions of the largest public housing projects.

Table 14 shows the heterogeneity over Census Tract characteristics, to help understand whether the heterogeneity of results found in the previous table are driven by the neighborhood containing the public housing, rather than the public housing itself. All Census tract characteristics are as of the 2000 Census, which is prior to most of the demolition activity. Income is the median household income in the Census tract, Poverty is percent of households below the poverty line, Density is measured by the population per square meter of land area, and the race/ethnicity variables are the percent of the population of that race/ethnicity. The median values of each of these tract characteristics are given at the bottom of the table, for context.

Public housing demolitions in low income and high density locations seem to be driving the effects on local crime. The effects are consistent across quantiles of poverty rates. Tracts with low percentage whites and high percentage blacks also carry the majority of the effect. Tracts with the lowest percent black appear to experience crime increases rather than decreases after a demolition. Not only may the characteristics of the public housing be important for the effect the demolition of a public housing complex might have, but the surrounding neighborhood may be important too.

Tables 13 and 14 show that poorly maintained, large public housing structures in high density, low income, and high percent minority neighborhoods were the primary drivers of the estimated externalities from the public housing. This paper does not suggest that the "publicness" of the public housing drives the externalities, nor that low income housing universally imposes externalities on the neighborhood. If that were the case, the per-unit 
effect should be uniform across both the characteristics of the public housing complexes and across the neighborhood characteristic distribution.

\section{Discussion \& Conclusion}

The goal of this paper is to analyze the externalities of public housing on the surrounding neighborhood using the change in public housing stock from demolition of severely distressed buildings. I am able to identify very local effects of these demolitions using geographically detailed data on crimes and demolition locations. This data availability allows me to do a modified difference in difference and an event study using the variation in the location, scale, and timing of the demolitions.

Using this data, I find statistically significant decreases in crime within a $1 / 4$ mile of the demolition and no indication of spatial redistribution of crime. The effect is concentrated in highly costly violent crimes, with assaults declining far more sharply than burglaries, robberies and thefts. These declines occur at the time the residents are evicted from the public housing and persist at least 5 years after the demolition. Chicago's public housing demolitions may provide an upper bound of the neighborhood effects of demolishing distressed public housing units because Chicago's public housing was above average in its need for renovation. However, the improvements to the neighborhood found in this paper are encouraging with respect to other demolition programs currently occurring in many US cities.

These findings clearly indicate that the demolished housing imposed negative externalities on the surrounding neighborhood. These externalities should be incorporated into future decisions regarding low income housing. The large size and poor maintenance of the low income housing studied here were the most important factors driving the effect of the crime decrease, and these factors should be kept in mind in particular as future housing decisions are made. Further research is needed to understand the full interactions between low income housing and the effect on the surrounding neighborhood. Without understanding these interactions thoroughly, we will continue to struggle to find a way to construct and maintain low income housing such that it does not impose externalities on the surrounding neighborhood. There remains a strong need for adequate housing for low income individuals. How to fulfill that need in a socially optimal way remains a challenge. 


\section{References}

Aliprantis, Dionissi and Daniel A. Hartley, "Blowing it Up and Knocking it Down: The Local and Citywide Effects of Demolishing High-Concentration Public Housing on Crime," Journal of Urban Economics, July 2015, 88, 67--81.

Andersson, Fredrik, John C Haltiwanger, Mark J Kutzbach, Giordano Palloni, Henry O Pollakowski, and Daniel H Weinberg, "Childhood Housing And Adult Earnings: A Between-Siblings Analysis Of Housing Vouchers And Public Housing," US Census Bureau Center for Economic Studies Paper No. CES-WP-13-48, 2013.

Burbidge, John B., Lonnie Magee, and A. Leslie Robb, "Alternative Transformations to Handle Extreme Values of the Dependent Variables," Journal of the American Statistical Association, 1988, 83 (401), 123-127.

Buron, Larry and Susan J. Popkin, "After Wells: Where Are the Residents Now?," Technical Report, Urban Institute August 2010. Program on Neighborhoods and Youth Development.

Corman, Hope and Naci Mocan, "Carrots, Sticks, and Broken Windows*," Journal of Law and Economics, 2005, 48 (1), 235-266.

Eriksen, Michael D. and Stuart S. Rosenthal, "Crowd Out Effects of Place-Based Subsidized Rental Housing: New Evidence From the LIHTC Program," Journal of Public Economics, December 2010, 94, 953-966.

Glaeser, Edward L. and Bruce Sacerdote, "Why Is There More Crime in Cities?," Journal of Political Economy, December 1999, 107 (6), S225-S257.

Gleick, Elizabeth and Julie Grace, "Belated Outrage for Girl X," Time Magazine February 1997. http://www.time.com/time/magazine/article/0,-9171,985957,00.html.

Hunt, D. Bradford, Blueprint for Disaster: The Unraveling of Chicago Public Housing Historical Studies of Urban America, Chicago and London: The University of Chicago Press, 2009. 
Jacob, Brian A., "Public Housing, Housing Vouchers, and Student Achievement: Evidence from Public Housing Demolitions in Chicago," The American Economic Review, March 2004, 94 (1), 233-258.

Jacob, Brian and Jens Ludwig, "The Effects of Housing Assistance on Labor Supply: Evidence from a Voucher Lottery," American Economic Review, February 2012, 102 (1), 272-304.

_ _ _ a a a Douglas Miller, "The Effects of Housing and Neighborhood Conditions on Child Mortality," Journal of Health Economics, January 2013, 32 (1), 195-206.

Jacobs, Jane, The Death and Life of Great American Cities, Random House LLC, 1961.

Kirby, Joseph A., "The Death of Dantrell Davis," Chicago Tribune October 1992. http://www.chicagotribune.com/news/politics/chi-chicagodays-dantrelldavisstory, 0,6132262 .story.

Kling, Jeffrey R., Jeffrey B. Liebman, and Lawrence F. Katz, "Experimental Analysis of Neighborhood Effects," Econometrica, January 2007, 75 (1), 83-119.

_ _ Jens Ludwig, and Lawrence F. Katz, "Neighborhood Effects on Crime for Female and Male Youth: Evidence from a Randomized Housing Voucher Experiment," The Quarterly Journal of Economics, February 2005, 120 (1), 87-130.

Kuczka, Susan and Flynn McRoberts, "5-year-old was killed over candy," Chicago Tribune October 1994. http://www.chicagotribune.com/news/local/chi-941015-ericmorse, 0,1011760 .story.

Ludwig, Jens, Greg J. Duncan, and Paul Hirschfield, "Urban Poverty and Juvenile Crime: Evidence from a Randomized Housing-Mobility Experiment," Quarterly Journal of Economics, May 2001, 116 (2), 655-679.

National Commission On Severely Distressed Public Housing, "The Final Report of the National Commission on Severely Distressed Public Housing," Technical Report, US Deptartment of Housing and Urban Development August 1992.

Newman, Oscar, Defensible space, Macmillan New York, 1972. 
Popkin, Susan J., V.E. Gwiasda, J.M. Amendolia, and A.A. Anderson, The Hidden War: The Battle to Control Crime in Chicago's Public Housing, Abt Associates, 1996.

Sanbonmatsu, Lisa, Jeffrey R. Kling, Greg J. Duncan, and Jeanne Brooks-Gunn, "Neighborhoods and Academic Achievement: Results From the Moving to Opportunity Experiment," The Journal of Human Resources, 2006, 41 (4), 649-691.

Sandler, Danielle H. and Ryan Sandler, "Multiple event studies in public finance and labor economics: A simulation study with applications," The Journal of Economics and Social Measurement, September 2014, 39 (1-2), 31-57.

Venkatesh, Sudhir, American Project: The Rise and Fall of a Modern Ghetto, Harvard University Press, 2000.

_ _ Isil Celimi, and Beauty Turner, "The Robert Taylor Homes Relocation Study," Technical Report, Center for Urban Research and Policy September 2002.

, Isil Çelimli, Douglas Miller, Alexandra Murphy, and Beauty Turner, "Chicago Public Housing Transformation: A Research Report," Technical Report, Center for Urban Research and Policy, Columbia University in the City of New York February 2004. Working Paper. 


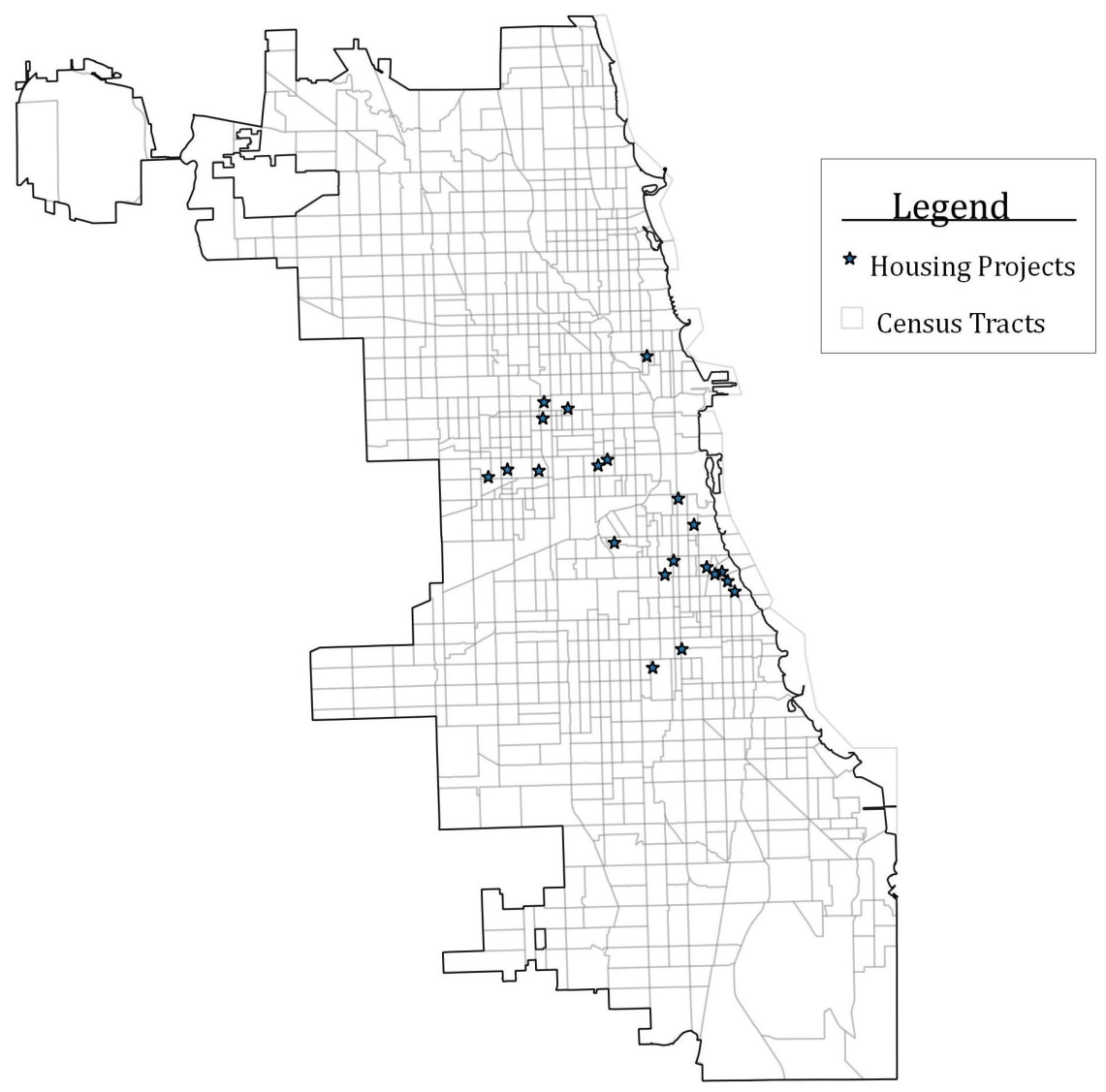

Figure 1: Demolished Housing Projects, 1995-2010. Demolition addresses provided by the Chicago Housing Authority. 


$\overbrace{\begin{array}{c}\text { Demolition } \\ \text { Announced }\end{array}}^{\begin{array}{c}\text { Eviction } \\ \text { Notice }\end{array}} \begin{gathered}\begin{array}{c}\text { Building } \\ \text { Closure }\end{array} \\ \begin{array}{c}\text { Structural } \\ \text { Demolition }\end{array}\end{gathered}$

Figure 2: Demolition Timeline. Estimated from data provided by and personal communications with officials at the Chicago Housing Authority. 
Crimes in Chicago, 1999-2010

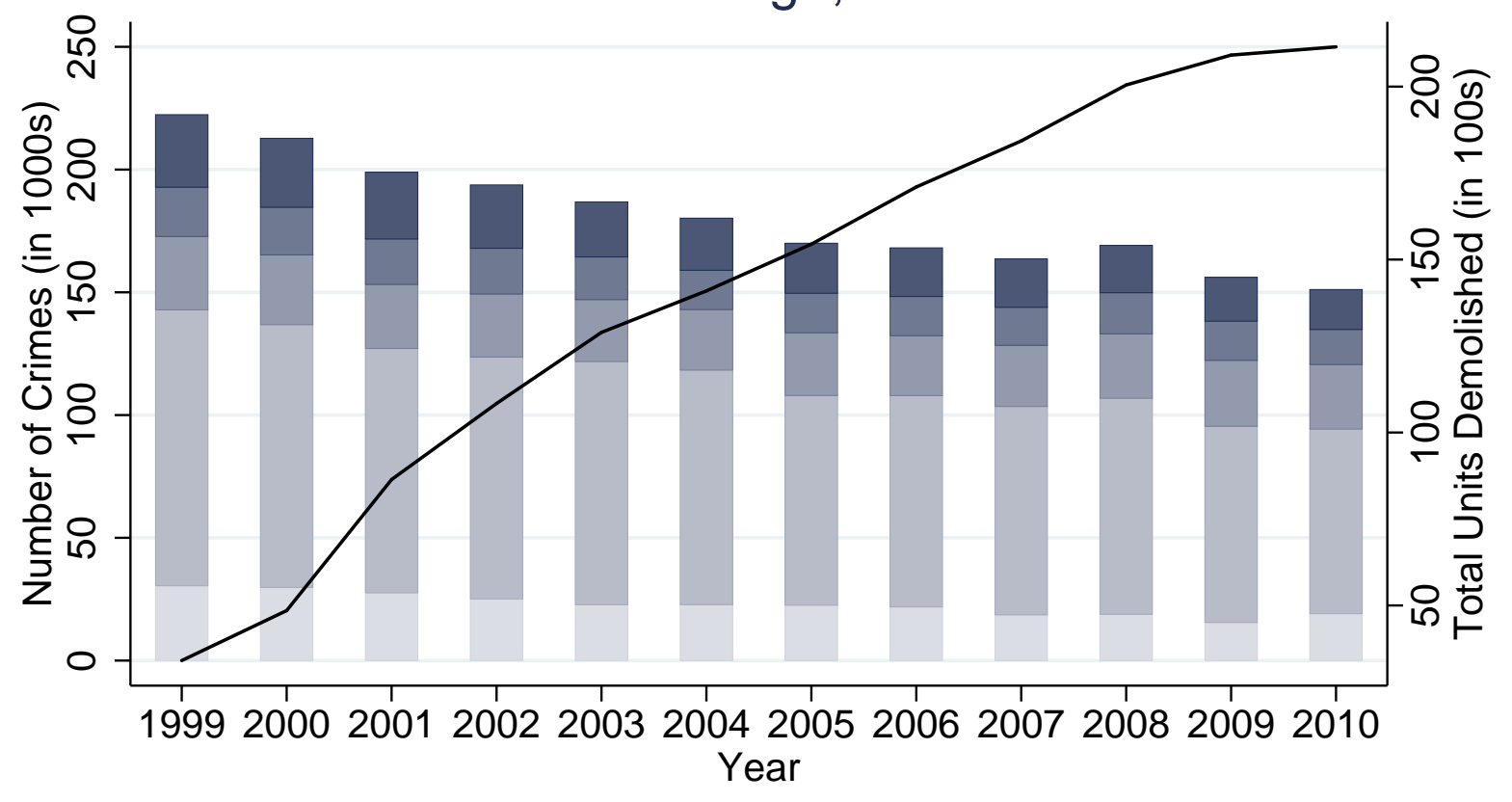

\begin{tabular}{|l|l|}
\hline Violent Crime & Robbery \\
Burglary & Theft \\
Car Theft & Units Demolished \\
\hline
\end{tabular}

Figure 3: Crime data aggregated from incident-level data provided by the Chicago Police Department. Aggregate public housing units demolished from data provided by the Chicago Housing Authority. 
Treated

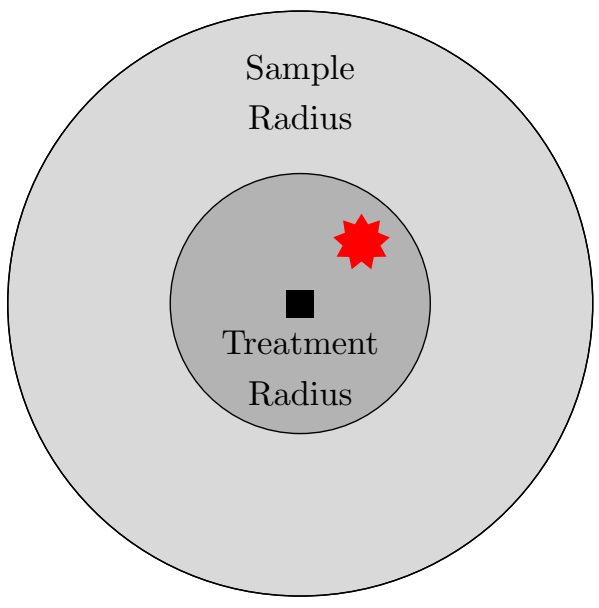

Control

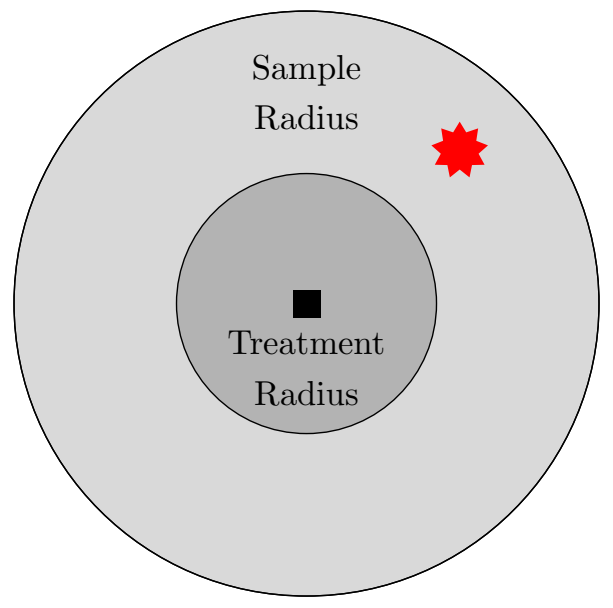

Not In Sample

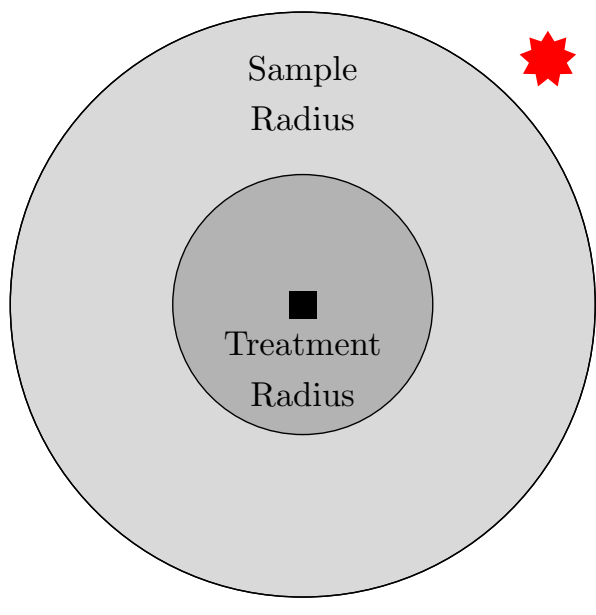

Figure 4: Assignment of Treatment Status 


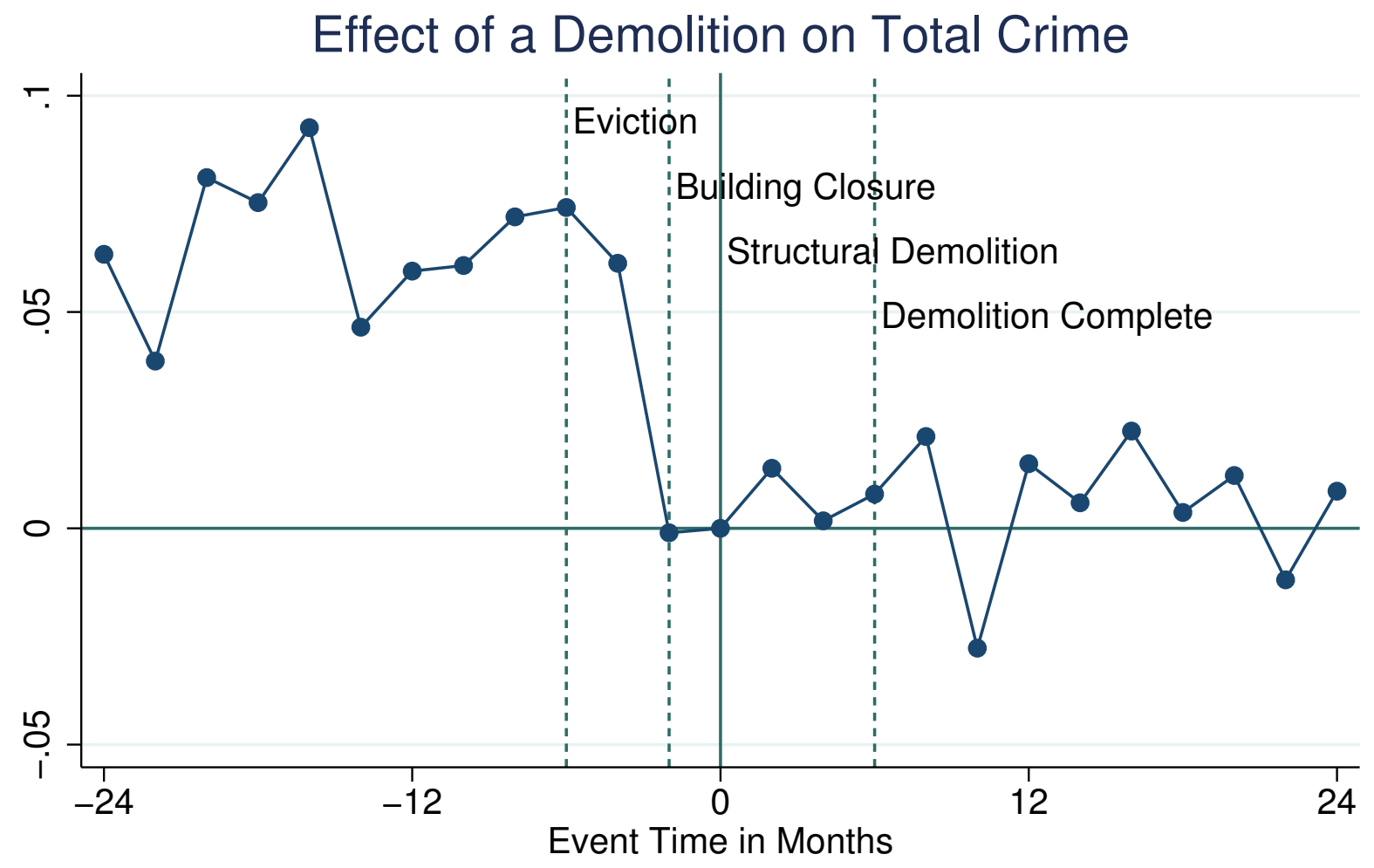

Dependent Variable is the total crime committed within a 1/4 mile of the demolition, and the unit of observation is a block-month. Coefficients are adjusted so that the coefficient for event time zero equals zero. Regression controls for state and year fixed effects.

Figure 5: Two Year Event Study 


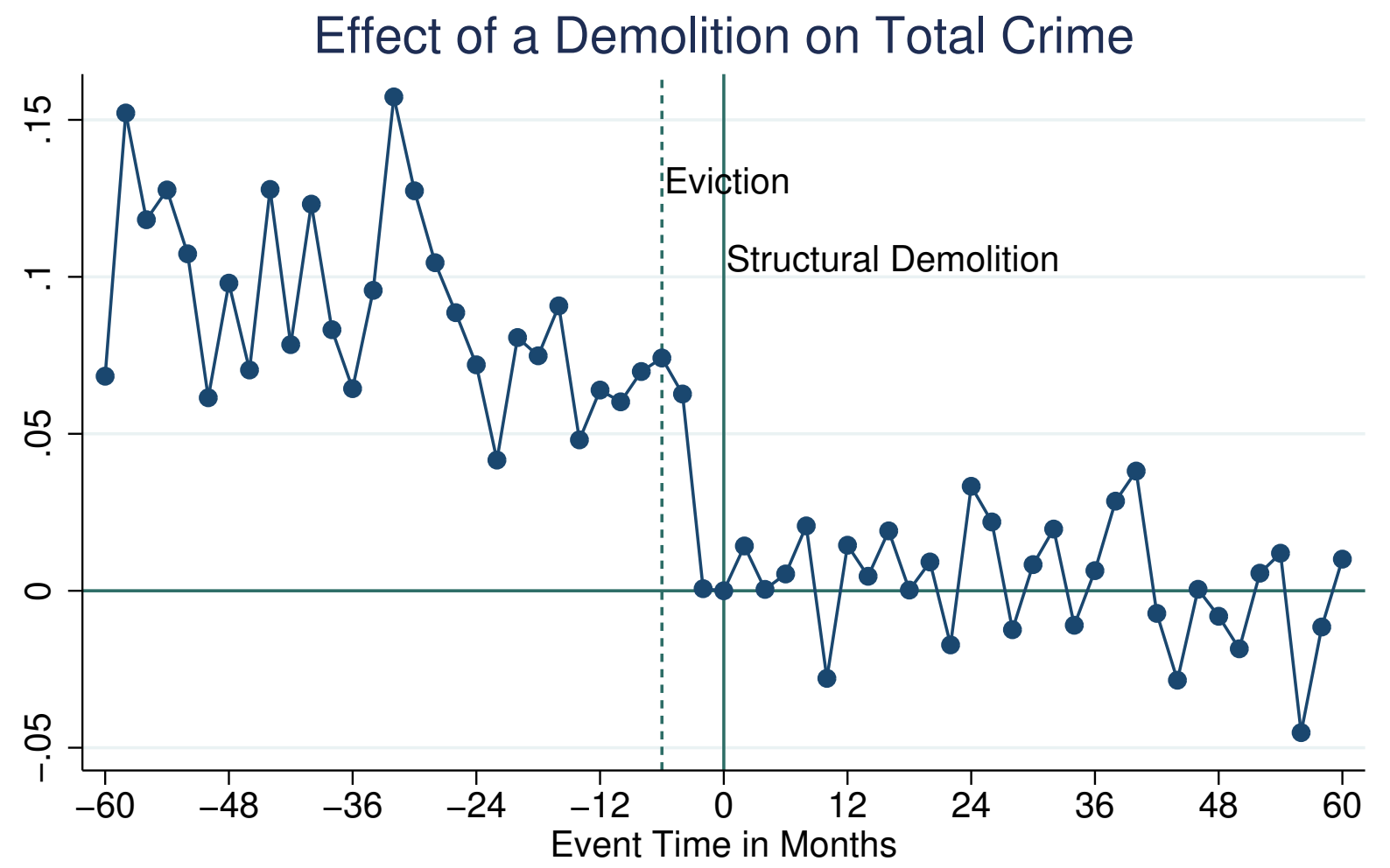

Dependent Variable is the total crime committed within a 1/4 mile of the demolition, and the unit of observation is a block-month. Coefficients are adjusted so that the coefficient for event time zero equals zero. Regression controls for state and year fixed effects.

Figure 6: Five Year Event Study 
Table 1: Number of Demolitions by Year

\begin{tabular}{cccc}
\hline & Demolitions & Average Units & Total Units \\
\hline 1995 & 2 & 98 & 197 \\
1996 & 5 & 142 & 711 \\
1997 & 5 & 134 & 672 \\
1998 & 8 & 94 & 756 \\
1999 & 5 & 214 & 1070 \\
2000 & 8 & 181 & 1445 \\
2001 & 13 & 291 & 3789 \\
2002 & 20 & 110 & 2199 \\
2003 & 40 & 51 & 2056 \\
2004 & 19 & 63 & 1200 \\
2005 & 50 & 27 & 1350 \\
2006 & 24 & 69 & 1654 \\
2007 & 19 & 70 & 1331 \\
2008 & 38 & 43 & 1618 \\
2009 & 16 & 54 & 864 \\
2010 & 4 & 60 & 239 \\
\hline Total & 276 & 77 & 21151 \\
\hline
\end{tabular}


Table 2: Number of Demolitions by Housing Complex

\begin{tabular}{lccc}
\hline & Demolitions & Average Units & Total Units \\
\hline ABLA & 46 & 63 & 2888 \\
Bridgeport Homes & 1 & 21 & 21 \\
Cabrini-Green & 17 & 154 & 2625 \\
Darrow Homes & 4 & 120 & 480 \\
Henry Horner Homes & 13 & 128 & 1665 \\
Ickes Homes & 8 & 83 & 666 \\
Lake Michigan Homes & 1 & 607 & 607 \\
Lawndale Complex & 2 & 120 & 239 \\
Madden Park & 11 & 44 & 487 \\
Maplewood Courts & 1 & 132 & 132 \\
Moorehead & 2 & 16 & 33 \\
Ogden Courts & 2 & 68 & 136 \\
Pinnacle & 1 & 16 & 16 \\
Prairie Courts & 1 & 203 & 203 \\
Robert Taylor Homes & 21 & 209 & 4389 \\
Rockwell Gardens & 7 & 162 & 1134 \\
Scattered Sites & 5 & 9 & 46 \\
Stateway Gardens & 8 & 206 & 1644 \\
Washington Park & 25 & 54 & 1362 \\
Wells Homes & 98 & 23 & 2300 \\
Wentworth Gardens & 2 & 39 & 78 \\
\hline Total & 276 & 77 & 21151 \\
\hline
\end{tabular}


Table 3: Average Monthly Crime by Block

\begin{tabular}{lcccc}
\hline & \multicolumn{4}{c}{ Distance From Demolition } \\
\cline { 2 - 5 } & 3 Miles & 1 Mile & $\frac{1}{2}$ Mile & $\frac{1}{4}$ Mile \\
\hline Total Crime & 0.851 & 0.880 & 0.908 & 0.924 \\
& $(1.689)$ & $(1.902)$ & $(2.098)$ & $(2.063)$ \\
Murder & 0.00277 & 0.00272 & 0.00296 & 0.00356 \\
& $(0.0554)$ & $(0.0547)$ & $(0.0577)$ & $(0.0629)$ \\
Assault & 0.0995 & 0.103 & 0.116 & 0.136 \\
& $(0.361)$ & $(0.378)$ & $(0.413)$ & $(0.473)$ \\
Rape & 0.00877 & 0.00844 & 0.00882 & 0.00989 \\
& $(0.0954)$ & $(0.0935)$ & $(0.0957)$ & $(0.102)$ \\
Robbery & 0.0833 & 0.0801 & 0.0869 & 0.0979 \\
& $(0.328)$ & $(0.325)$ & $(0.340)$ & $(0.364)$ \\
Burglary & 0.116 & 0.0986 & 0.0938 & 0.0939 \\
Theft & $(0.387)$ & $(0.362)$ & $(0.354)$ & $(0.358)$ \\
& 0.434 & 0.488 & 0.506 & 0.490 \\
Car Theft & $(1.336)$ & $(1.576)$ & $(1.762)$ & $(1.669)$ \\
& 0.103 & 0.0950 & 0.0910 & 0.0889 \\
Arson & $(0.346)$ & $(0.335)$ & $(0.328)$ & $(0.330)$ \\
& 0.00378 & 0.00328 & 0.00303 & 0.00288 \\
Drug Arrests & $(0.0637)$ & $(0.0595)$ & $(0.0565)$ & $(0.0549)$ \\
& 0.288 & 0.315 & 0.364 & 0.451 \\
Blocks & $(1.473)$ & $(1.629)$ & $(1.771)$ & $(2.089)$ \\
\hline Averge & 11,584 & 5,692 & 2,705 & 1,172 \\
\hline
\end{tabular}

Average crime by block from data provided by Chicago Police Department. Standard deviation in parentheses. 
Table 4: Average Monthly Crime by Block and Year, $\frac{1}{4}$ Mile from Demolition

\begin{tabular}{lcccc}
\hline & 1999 & $2000-2005$ & $2006-2010$ & 2011 \\
\hline Total Crime & 1.339 & 1.012 & 0.749 & 0.477 \\
& $(2.529)$ & $(2.164)$ & $(1.818)$ & $(1.432)$ \\
Murder & 0.00540 & 0.00436 & 0.00229 & 0.00213 \\
& $(0.0752)$ & $(0.0702)$ & $(0.0501)$ & $(0.0461)$ \\
Assault & 0.225 & 0.164 & 0.0883 & 0.0427 \\
& $(0.644)$ & $(0.535)$ & $(0.333)$ & $(0.220)$ \\
Rape & 0.0170 & 0.0115 & 0.00673 & 0.00555 \\
& $(0.136)$ & $(0.109)$ & $(0.0833)$ & $(0.0743)$ \\
Robbery & 0.149 & 0.107 & 0.0789 & 0.0525 \\
& $(0.467)$ & $(0.380)$ & $(0.320)$ & $(0.265)$ \\
Burglary & 0.133 & 0.0961 & 0.0848 & 0.0538 \\
& $(0.441)$ & $(0.359)$ & $(0.339)$ & $(0.289)$ \\
Theft & 0.680 & 0.529 & 0.413 & 0.259 \\
& $(1.918)$ & $(1.736)$ & $(1.537)$ & $(1.243)$ \\
Car Theft & 0.124 & 0.0975 & 0.0724 & 0.0602 \\
& $(0.393)$ & $(0.346)$ & $(0.295)$ & $(0.265)$ \\
Arson & 0.00462 & 0.00327 & 0.00212 & 0.000853 \\
& $(0.0699)$ & $(0.0587)$ & $(0.0469)$ & $(0.0292)$ \\
Drug Arrests & 0.510 & 0.582 & 0.292 & 0.179 \\
& $(1.821)$ & $(2.600)$ & $(1.335)$ & $(0.712)$ \\
\hline \hline
\end{tabular}

Average crime by block from data provided by Chicago Police Department. Standard deviation in parentheses. Years are relative to date of crime, not date of demolition 
Table 5: The Effect of Public Housing Demolitions on Crime

\begin{tabular}{lcccccc}
\hline & Total & Murder & Assault & Robbery & Burglary & Theft \\
\hline .25 mile & $-0.047^{* * *}$ & $-0.0005^{* * *}$ & $-0.020^{* * *}$ & $-0.009^{* * *}$ & $-0.003^{* *}$ & $-0.0105^{* *}$ \\
& $(0.0089)$ & $(0.0001)$ & $(0.0032)$ & $(0.0016)$ & $(0.0011)$ & $(0.0040)$ \\
.5 mile & $-0.016^{* * *}$ & -0.0001 & $-0.006^{* * *}$ & $-0.003^{* * *}$ & -0.001 & $-0.0058^{* *}$ \\
& $(0.0034)$ & $(0.0001)$ & $(0.0010)$ & $(0.0006)$ & $(0.0005)$ & $(0.0022)$ \\
.75 mile & $-0.006^{* *}$ & $-0.0001^{* *}$ & $-0.003^{* * *}$ & $-0.001^{* * *}$ & 0.000 & -0.0016 \\
& $(0.0022)$ & $(0.0000)$ & $(0.0006)$ & $(0.0003)$ & $(0.0003)$ & $(0.0016)$ \\
1 mile & $-0.003^{*}$ & $-0.0001^{* *}$ & $-0.002^{* * *}$ & $-0.001^{* * *}$ & -0.000 & -0.0000 \\
& $(0.0014)$ & $(0.0000)$ & $(0.0004)$ & $(0.0002)$ & $(0.0002)$ & $(0.0010)$ \\
\hline Mean & 0.851 & 0.003 & 0.099 & 0.083 & 0.116 & 0.434 \\
Blocks & 11,584 & 11,584 & 11,584 & 11,584 & 11,584 & 11,584 \\
\hline
\end{tabular}

Specification includes all blocks within a 3 mile radius of a demolition. Radius gives the treatment radius. The treatment variable is a running variable of the number of units demolished. Each element in the table is from a separate regression and reports coefficient on this treatment variable. All regressions include controls for month fixed effects and block fixed effects and a census tract specific time trend. Standard errors (in parentheses) are clustered at the block level. ${ }^{*} \mathrm{p}<0.05,{ }^{* *} \mathrm{p}<0.01,{ }^{* * *} \mathrm{p}<0.001$ 
Table 6: Interpretation Table for 1/4 Mile Treatment Radius

\begin{tabular}{lcccccc}
\hline & Total & Murder & Assault & Robbery & Burglary & Theft \\
\hline Average Demolition Size (100s) & 1.600 & 1.600 & 1.600 & 1.600 & 1.600 & 1.600 \\
Average Blocks per Demolition & 27 & 27 & 27 & 27 & 27 & 27 \\
Treatment Coefficient & -0.0467 & -0.000543 & -0.0201 & -0.00881 & -0.00301 & -0.0105 \\
Average Crime Per Block & 0.851 & 0.00277 & 0.0995 & 0.0833 & 0.116 & 0.434 \\
Treatment Per Block & -0.0748 & -0.000869 & -0.0322 & -0.0141 & -0.00481 & -0.0168 \\
Treatment Per Demolition & -2.019 & -0.0235 & -0.870 & -0.381 & -0.130 & -0.454 \\
Percent of Average Crime & -0.0879 & -0.314 & -0.324 & -0.169 & -0.0417 & -0.0388 \\
& & & & & & \\
\hline
\end{tabular}

Coefficients from main specification in Table 5. Average demolition size and number of blocks only include demolitions in the estimating sample with more than 75 units. Treatment per block=Average demolition size*Units Coefficient. Treatment per demolition multiplies the treatment per block by the average number of blocks. Percent of average crime divides the treatment per block by the average number of crimes of that type per block. 
Table 7: Estimates of Public Housing on Crime with No Block of Demolition

\begin{tabular}{lcccccc}
\hline & Total & Murder & Assault & Robbery & Burglary & Theft \\
\hline \multirow{2}{*}{.25 mile } & -0.014 & $-0.0004^{*}$ & -0.004 & -0.003 & 0.001 & -0.0076 \\
& $(0.0126)$ & $(0.0002)$ & $(0.0027)$ & $(0.0023)$ & $(0.0014)$ & $(0.0086)$ \\
.5 mile & $-0.010^{*}$ & -0.0001 & $-0.002^{*}$ & $-0.002^{* * *}$ & 0.001 & $-0.0071^{*}$ \\
& $(0.0037)$ & $(0.0001)$ & $(0.0007)$ & $(0.0006)$ & $(0.0006)$ & $(0.0029)$ \\
\multirow{2}{*}{ 75 mile } & -0.003 & -0.0001 & $-0.001^{* *}$ & $-0.001^{* *}$ & 0.000 & -0.0014 \\
& $(0.0022)$ & $(0.0000)$ & $(0.0004)$ & $(0.0003)$ & $(0.0003)$ & $(0.0018)$ \\
1 mile & -0.001 & -0.0000 & $-0.001^{* *}$ & $-0.001^{* *}$ & 0.000 & 0.0001 \\
& $(0.0014)$ & $(0.0000)$ & $(0.0002)$ & $(0.0002)$ & $(0.0002)$ & $(0.0011)$ \\
\hline Mean & 0.849 & 0.003 & 0.096 & 0.082 & 0.117 & 0.435 \\
Blocks & 11,108 & 11,108 & 11,108 & 11,108 & 11,108 & 11,108 \\
\hline
\end{tabular}

Specification includes all blocks within a 3 mile radius of a demolition. Radius gives the treatment radius. The treatment variable is a running variable of the number of units demolished. Each element in the table is from a separate regression and reports coefficient on this treatment variable. All regressions include controls for month fixed effects and block fixed effects and a census tract specific time trend. SStandard errors (in parentheses) are clustered at the block level. ${ }^{*} \mathrm{p}<0.05,{ }^{*} \mathrm{p}<0.01,{ }^{* * *} \mathrm{p}<0.001$ 
Table 8: Treatment Effect Over Space

\begin{tabular}{ccccccc}
\hline & Total & Murder & Assault & Robbery & Burglary & Theft \\
\hline .25 mile & $-0.041^{* * *}$ & $-0.0006^{* * *}$ & $-0.019^{* * *}$ & $-0.008^{* * *}$ & $-0.003^{*}$ & -0.006 \\
& $(0.0106)$ & $(0.0002)$ & $(0.0036)$ & $(0.0018)$ & $(0.0013)$ & $(0.0057)$ \\
.5 mile & -0.006 & 0.0000 & -0.001 & $-0.001^{*}$ & 0.000 & -0.004 \\
& $(0.0041)$ & $(0.0001)$ & $(0.0011)$ & $(0.0006)$ & $(0.0006)$ & $(0.0030)$ \\
\hline .25 mile & $-0.046^{* * *}$ & $-0.0005^{* * *}$ & $-0.020^{* * *}$ & $-0.009^{* * *}$ & $-0.003^{* *}$ & $-0.011^{*}$ \\
& $(0.0091)$ & $(0.0001)$ & $(0.0032)$ & $(0.0016)$ & $(0.0011)$ & $(0.0042)$ \\
1 mile & -0.001 & $-0.0001^{*}$ & $-0.001^{*}$ & -0.000 & 0.000 & 0.000 \\
& $(0.0015)$ & $(0.0000)$ & $(0.0004)$ & $(0.0002)$ & $(0.0002)$ & $(0.0011)$ \\
\hline .5 mile & $-0.016^{* * *}$ & -0.0001 & $-0.005^{* * *}$ & $-0.003^{* * *}$ & -0.001 & $-0.007^{* *}$ \\
& $(0.0038)$ & $(0.0001)$ & $(0.0010)$ & $(0.0006)$ & $(0.0005)$ & $(0.0025)$ \\
1 mile & 0.000 & $-0.0001^{*}$ & -0.001 & -0.000 & 0.000 & 0.001 \\
& $(0.0016)$ & $(0.0000)$ & $(0.0004)$ & $(0.0002)$ & $(0.0002)$ & $(0.0012)$ \\
\hline 1 mile & -0.003 & $-0.0001^{* *}$ & $-0.001^{* * *}$ & $-0.001^{* *}$ & -0.000 & 0.000 \\
& $(0.0017)$ & $(0.0000)$ & $(0.0004)$ & $(0.0002)$ & $(0.0002)$ & $(0.0012)$ \\
2 miles & -0.000 & 0.0000 & -0.000 & 0.000 & 0.000 & -0.000 \\
& $(0.0009)$ & $(0.0000)$ & $(0.0002)$ & $(0.0001)$ & $(0.0001)$ & $(0.0008)$ \\
\hline Blocks & 11,584 & 11,584 & 11,584 & 11,584 & 11,584 & 11,584 \\
\hline
\end{tabular}

Specification includes all blocks within a 3 mile radius of a demolition. Radius gives the treatment radius. Units is a running variable of the number of units demolished. All regressions include controls for month fixed effects and block fixed effects and a census tract specific time trend. Standard errors (in parentheses) are clustered at the block level. * $\mathrm{p}<0.05,{ }^{* *} \mathrm{p}<0.01,{ }^{* * *} \mathrm{p}<0.001$ 
Table 9: Robustness Check: Using Only Variation in Timing

\begin{tabular}{lcccccc}
\hline & Total & Murder & Assault & Robbery & Burglary & Theft \\
\hline .25 mile & $-0.050^{* * *}$ & $-0.0005^{* *}$ & $-0.022^{* * *}$ & $-0.009^{* * *}$ & $-0.004^{* *}$ & $-0.0106^{*}$ \\
& $(0.0099)$ & $(0.0002)$ & $(0.0035)$ & $(0.0017)$ & $(0.0013)$ & $(0.0047)$ \\
.5 mile & $-0.015^{* * *}$ & -0.0001 & $-0.006^{* * *}$ & $-0.003^{* * *}$ & -0.001 & -0.0036 \\
& $(0.0034)$ & $(0.0001)$ & $(0.0011)$ & $(0.0006)$ & $(0.0005)$ & $(0.0020)$ \\
.75 mile & $-0.005^{*}$ & $-0.0001^{* *}$ & $-0.003^{* * *}$ & $-0.001^{* * *}$ & -0.000 & -0.0003 \\
& $(0.0022)$ & $(0.0000)$ & $(0.0006)$ & $(0.0003)$ & $(0.0003)$ & $(0.0015)$ \\
1 mile & -0.002 & $-0.0001^{* *}$ & $-0.002^{* * *}$ & $-0.001^{* *}$ & -0.000 & 0.0011 \\
& $(0.0015)$ & $(0.0000)$ & $(0.0004)$ & $(0.0002)$ & $(0.0002)$ & $(0.0011)$ \\
\hline Mean & 0.880 & 0.003 & 0.103 & 0.080 & 0.099 & 0.488 \\
Blocks & 5,692 & 5,692 & 5,692 & 5,692 & 5,692 & 5,692 \\
\hline
\end{tabular}

Specification includes only blocks within the listed radius of the demolition, using no variation in distance. The treatment variable is a running variable of the number of units demolished. Each element in the table is from a separate regression and reports coefficient on this treatment variable. All regressions include controls for month fixed effects and block fixed effects and a census tract specific time trend. Standard errors (in parentheses) are clustered at the block level. ${ }^{*} \mathrm{p}<0.05,{ }^{* *} \mathrm{p}<0.01,{ }^{* * *} \mathrm{p}<0.001$ 
Table 10: Robustness Check- Timing

\begin{tabular}{lcccc}
\hline & Eviction & Closure & Demolition & Completion \\
\hline .25 mile & $-0.052^{* * *}$ & $-0.049^{* * *}$ & $-0.047^{* * *}$ & $-0.044^{* * *}$ \\
& $(0.0092)$ & $(0.0089)$ & $(0.0089)$ & $(0.0089)$ \\
.5 mile & $-0.020^{* * *}$ & $-0.017^{* * *}$ & $-0.016^{* * *}$ & $-0.015^{* * *}$ \\
& $(0.0036)$ & $(0.0034)$ & $(0.0034)$ & $(0.0034)$ \\
.75 mile & $-0.009 * * *$ & $-0.007^{* *}$ & $-0.006^{* *}$ & $-0.006 * *$ \\
& $(0.0022)$ & $(0.0022)$ & $(0.0022)$ & $(0.0022)$ \\
1 mile & $-0.005^{* * *}$ & $-0.004^{* *}$ & $-0.003^{*}$ & -0.003 \\
& $(0.0014)$ & $(0.0014)$ & $(0.0014)$ & $(0.0015)$ \\
\hline Mean & 0.851 & 0.851 & 0.851 & 0.851 \\
Blocks & 11,584 & 11,584 & 11,584 & 11,584 \\
\hline
\end{tabular}

Specification includes all blocks within a 3 mile radius. The treatment variable is a running variable of the number of units demolished. Each element in the table is from a separate regression and reports coefficient on this treatment variable. All regressions include controls for month fixed effects and block fixed effects and a census tract specific time trend. Standard errors (in parentheses) are clustered at the block level. ${ }^{*} \mathrm{p}<0.05,{ }^{* *} \mathrm{p}<0.01,{ }^{* * *} \mathrm{p}<0.001$ 
Table 11: Robustness Checks

\begin{tabular}{lccccc}
\hline & Main & $\begin{array}{c}\text { Dummy } \\
\text { Treatment }\end{array}$ & No Trend & IHS & Poisson \\
\hline .25 Mile & $-0.047^{* * *}$ & 0.004 & $-0.067^{* * *}$ & $-0.024^{* *}$ & $-0.071^{* *}$ \\
& $(0.0089)$ & $(0.0364)$ & $(0.0085)$ & $(0.0033)$ & $(0.0060)$ \\
.5 Mile & $-0.016^{* * *}$ & -0.035 & $-0.024^{* * *}$ & $-0.006^{* *}$ & $-0.025^{* *}$ \\
& $(0.0034)$ & $(0.0255)$ & $(0.0027)$ & $(0.0012)$ & $(0.0024)$ \\
.75 Mile & $-0.006^{* *}$ & 0.005 & $-0.013^{* * *}$ & $-0.003^{* *}$ & $-0.014^{* *}$ \\
& $(0.0022)$ & $(0.0192)$ & $(0.0017)$ & $(0.0007)$ & $(0.0013)$ \\
1 Mile & $-0.003^{*}$ & -0.0001 & $-0.008^{* * *}$ & $-0.002^{* *}$ & $-0.009^{* *}$ \\
& $(0.0014)$ & $(0.0166)$ & $(0.0010)$ & $(0.0005)$ & $(0.0009)$ \\
\hline Mean & 0.851 & 0.851 & 0.851 & 0.851 & 0.851 \\
Blocks & 11,584 & 11,584 & 11,584 & 11,584 & 11,584 \\
\hline
\end{tabular}

Specification includes all blocks within a 3 mile radius of a demolition. In the main specification the treatment variable is a running variable of the number of units demolished. In the second specification, the treatment variable is dummy at the time of the first demolition. The third specification does not include a control for census-tract specific trends. In the fourth specification the linear count of crimes committed is used instead of the inverse hyperbolic sine. In the fifth specification the estimation is made with a maximum likelihood estimation using a Poisson distribution. Incident rate ratios are reported. 
Table 12: Event Study

\begin{tabular}{cccc}
\hline & & & \\
\hline 23-24 Months Before & 0.039 & $1-2$ Months After & -0.010 \\
& $(0.008)$ & & $(0.023)$ \\
21-22 Months Before & 0.015 & $3-4$ Months After & -0.022 \\
& $(0.023)$ & & $(0.023)$ \\
19-20 Months Before & 0.057 & $5-6$ Months After & -0.016 \\
& $(0.023)$ & & $0.023)$ \\
17-18 Months Before & 0.051 & $7-8$ Months After & -0.003 \\
& $(0.023)$ & & $(0.022)$ \\
& 0.069 & $9-10$ Months After & -0.052 \\
15-16 Months Before & $(0.023)$ & & $(0.023)$ \\
& 0.022 & $11-12$ Months After & -0.009 \\
13-14 Months Before & $(0.023)$ & & $0.023)$ \\
& 0.035 & $13-14$ Months After & -0.018 \\
11-12 Months Before & $(0.023)$ & & $(0.023)$ \\
& 0.037 & $15-16$ Months After & -0.002 \\
9-10 Months Before & $(0.023)$ & & $(0.023)$ \\
& & & \\
7-8 Months Before & 0.048 & $17-18$ Months After & -0.020 \\
& $(0.022)$ & & $(0.023)$ \\
5-6 Months Before & 0.050 & $19-20$ Months After & -0.012 \\
& $(0.023)$ & & $(0.023)$ \\
3-4 Months Before & 0.037 & $21-22$ Months After & -0.036 \\
& $(0.023)$ & & $(0.023)$ \\
1-2 Months Before & -0.025 & $23-24$ Months After & -0.015 \\
& $(0.023)$ & & $(0.007)$ \\
Month of Demoliton & -0.024 & & \\
& $(0.027)$ & & \\
\hline
\end{tabular}

Dependent variable is the total crime committed within a $1 / 4$ mile radius of the demolition and the unit of observation is the block-month. Regressions control for block and month fixed effects. 
Table 13: Heterogeneity Over Public Housing Characteristics

\begin{tabular}{lccc}
\hline \multicolumn{2}{c}{ Inspection Score } & \multicolumn{2}{c}{ Size (Total Units) } \\
\hline Very Low (0-40) & $-0.023^{*}$ & Small $(0-50)$ & 0.044 \\
& $(0.0139)$ & & $(1.0599)$ \\
Low (40-60) & $-0.054^{* *}$ & Medium (50-100) & 2.145 \\
& $(0.0187)$ & & $(0.5485)$ \\
Passing (60+) & 0.109 & Large (100+) & $-0.047^{* * *}$ \\
& $(1.9074)$ & & $(0.0033)$ \\
\hline Mean & 0.847 & & 0.851 \\
Blocks & 10,948 & & 11,584 \\
\hline
\end{tabular}

Specification includes all blocks within a 3 mile radius of a demolition. The treatment radius is set to .25 miles. Reported coefficients are the interaction between public housing characteristics and number of units demolished. All regressions include controls for month fixed effects and block fixed effects and a census tract specific time trend. Standard errors (in parentheses) are clustered at the block level. * $\mathrm{p}<0.05,{ }^{* *} \mathrm{p}<0.01,{ }^{* * *} \mathrm{p}<0.001$

Table 14: Heterogenity Over Census Tract Characteristics

\begin{tabular}{lcccccc}
\hline & Income & Poverty & Density & White & Black & Hispanic \\
\hline Quartile 1 & $-0.052^{* * *}$ & $-0.066^{*}$ & -0.044 & $-0.056^{* * *}$ & $0.712^{* * *}$ & $-0.058^{* * *}$ \\
& $(0.0001)$ & $(0.0003)$ & $(0.0002)$ & $(0.0001)$ & $(0.0021)$ & $(0.0001)$ \\
Quartile 2 & $-0.032^{*}$ & 0.069 & -0.027 & -0.030 & -0.028 & -0.020 \\
& $(0.0001)$ & $(0.0006)$ & $(0.0001)$ & $(0.0002)$ & $(0.0002)$ & $(0.0002)$ \\
Quartile 3 & 0.124 & -0.044 & $-0.053^{* * *}$ & 0.099 & -0.009 & 0.019 \\
& $(0.0008)$ & $(0.0003)$ & $(0.0002)$ & $(0.0005)$ & $(0.0002)$ & $(0.0003)$ \\
Quartile 4 & -0.007 & $-0.048^{* * *}$ & $-0.058^{* *}$ & 0.092 & $-0.055^{* * *}$ & $-0.067^{*}$ \\
& $(0.0003)$ & $(0.0001)$ & $(0.0002)$ & $(0.0216)$ & $(0.0001)$ & $(0.0003)$ \\
\hline Blocks & 11,584 & 11,486 & 11,584 & 11,560 & 11,560 & 11,560 \\
Median & 32,125 & 23.1 & .0062 & 23.4 & 58.2 & 4.6 \\
\hline
\end{tabular}

Specification includes all blocks within a 3 mile radius of a demolition. Reported coefficients are the interaction between census block characteristic quartiles and number of units demolished. All regressions include controls for month fixed effects and block fixed effects and a census tract specific time trend. Standard errors (in parentheses) are clustered at the block level. ${ }^{*} \mathrm{p}<0.05$, ${ }^{* *} \mathrm{p}<0.01,{ }^{* * *} \mathrm{p}<0.001$ 